\title{
EIS RESEARCH OF AW-7020 ALLOY JOINTS WELDED BY MIG
}

\author{
Krzysztof Dudzik, Adam Charchalis \\ Gdynia Maritime University, Faculty of Marine Engineering \\ Morska Street 81-87, 81-225 Gdynia, Poland \\ tel.:+48586901549, +485869013 47, fax: +48586901399 \\ e-mail:kdudzik@am.gdynia.pl,achar@am.gdynia.pl
}

\begin{abstract}
The results of corrosion properties research of aluminum alloy AW 7020 (AlZn5Mg1) welded by MIG were presented. In the article the parameters for MIG welding of sheets made of AlZn5Mg1 (7020) alloy was presented. Metallographic analysis of bonds showed a proper structural construction MIG welded 7020 aluminum alloy.

EIS measurement was performed in three electrode system in artificial seawater $(3.5 \% \mathrm{NaCl})$. Impedance studies were carried out at the corrosion potential. Changed voltage signal amplitude in the range $\pm 10 \mathrm{mV}$ and frequency range of changes was as follows: $100 \mathrm{kHz}-0.1 \mathrm{~Hz}$. Atlas $0531 \mathrm{EU} \& \mathrm{IA}$ potentiostat was used for studies. Model in the form of an electrical equivalent circuit replacement was chosen for the test object. The results of electrochemical impedance spectroscopy are presented graphically in the Nyquist charts matched with the theoretical curve to them and in the form of parameters characterizing the corrosion process. Obtained results were statistically analyzed.

Much better resistance to electrochemical corrosion was found for the native material then joint welded by MIG of 7020 aluminum alloy. The most important parameter - charge transfer resistance value of a double layer $R_{c t}$ for sample of native material is higher than for the sample welded by MIG.

Original value is received results of the corrosion properties of MIG welded AlZn5Mg1 alloy compared with the native material.
\end{abstract}

Keywords: Electrochemical Impedance Spectroscopy (EIS), aluminium alloys, MIG welding, corrosion

\section{Introduction}

Aluminium alloys are getting more and more interest in the shipbuilding industry as these alloys allow a significant reduction in ship structure weight compared with the weight of steel structures. The use of aluminium reduces the weight by about $50 \%$, thereby increasing the displacement of the vessel and maintaining the displacement for load or speed increase and stability improvement. Among weldable Al-alloys suitable to plastic working the group of Al-Mg alloys (of 5xxx-series) of good weldability and relatively good service conditions are still the most popular. The advantage of these alloys is their relative insensitivity to layer corrosion and stress corrosion, the disadvantage - low strength of welded joints, below $300 \mathrm{MPa}$. An alternative to these alloys could be the Al-Zn-Mg (7xxx series) alloys. They exhibit higher strength properties than the mechanical properties of Al-Mg alloys. The disadvantage of the 7xxx series alloys is that they are prone to stress and layer corrosion. Many years of research have shown that the resistance of these alloys to stress corrosion is influenced among other things by heat processing, chemical composition and welding technology (welding method, type of fillers, type of joint) [1-5]. Virtually all joints welded using conventional MIG or TIG methods in this group of alloys possess insufficient resistance to stress or layer corrosion. Studies on the electrochemical corrosion resistance of AW-7020 alloy and its joints welded by MIG supplement knowledge about the environmental destruction of that material have been worked. Currently, one of the best research methods of resistance to this type of corrosion is electrochemical impedance spectroscopy (EIS). It allows you to not only determine the electrochemical corrosion resistance but also gives the opportunity to evaluate homogeneity of the corrosion process on the metal surface $[6,7,10]$.

The aim of this paper is to determine the susceptibility to the electrochemical corrosion of AW7020 (AlZn5Mg1) alloy joints welded by MIG in artificial seawater environment comparison to 
the native material.

\section{The research methodology}

The testing used EN AW-7020 T6 aluminium alloy (supersaturated and artificially aged) The chemical composition of the alloy is given in Tab. 1.

Tab. 1. Chemical composition of 7020 aluminum alloy

\begin{tabular}{|c|c|c|c|c|c|c|c|c|c|}
\hline \multicolumn{10}{|c|}{ Chemical composition (\%) } \\
\hline $\mathrm{Si}$ & $\mathrm{Fe}$ & $\mathrm{Cu}$ & $\mathrm{Mn}$ & $\mathrm{Mg}$ & $\mathrm{Cr}$ & $\mathrm{Zn}$ & $\mathrm{Ti}$ & $\mathrm{Zr}$ & $\mathrm{Al}$ \\
\hline 0.30 & 0.35 & 0.10 & 0.24 & 1.30 & 0.14 & 4.70 & 0.08 & 0.07 & the rest \\
\hline
\end{tabular}

Butt joints on thickness $\mathrm{g}=12 \mathrm{~mm}$ were made using MIG arc welding. Preparation of welded joints was carried out in accordance with procedures required by the shipbuilding industry. AlMg5 alloy (AG5 Nertalic SAF) wire was used for welding as filler. Shielding gas of argon with a purity of $99.99 \%$ was used. Welding parameters used to joining 7020 alloy sheets are shown in Tab. 2 .

Welds made by MIG method have been verified by X-ray flaw detection and showed no welding defects.

Tab. 2. MIG welding parameters of 7020 aluminum alloy sheets

\begin{tabular}{|c|c|c|c|}
\hline $\begin{array}{c}\text { Diameter of welding } \\
\text { wire [mm] }\end{array}$ & Welding current [A] & Voltage [V] & Number of layers \\
\hline 1.6 & $190-230$ & 4 + prewelding & $16-18$ \\
\hline
\end{tabular}

The corrosion resistance researches were carried out using three electrode method. Used in studies three electrode system consists of the following elements: the sample, an auxiliary electrode (polarizing) of titanium and platinum reference electrode (saturated calomel electrode) were placed in a tank with $3.5 \%$ water solution $\mathrm{NaCl}$. Active surface samples for the base metal was $1 \mathrm{~cm}^{2}$ and welded joints by MIG was $0.5 \mathrm{~cm}^{2}$. Samples attached to copper wires, PVC insulated. Not tested surface is isolated from the corrosive environment. Before the measurements the samples were exposed in the electrolyte to stabilize the corrosion potential. During measuring the electrolyte was continuously mixed using a magnetic stirrer [6-9]. The samples were degreased before the test.

Atlas 0531EU \& IA potentiostat was used for studies.

Electrochemical impedance spectroscopy measurements were conducted at the corrosion potential. The amplitude of the voltage signal varied in the range $\pm 10 \mathrm{mV}$, and the extent of the changes was the signal frequency: $100 \mathrm{kHz}-0.1 \mathrm{~Hz}$. Studies have been conducted from high to low frequencies [10].

Determination of the corrosion process parameters was performed computer programs: AtlasLab 2.0 and EIS Spectrum Analyzer.

Chosen for the test object model in the form of an electrical equivalent circuit of the replacement.

Selected model electrical circuit showing a replacement is presented in Fig. 1.

In the selected model, the $R_{S}$ element is the electrolyte resistance which is reflected in corrosive environment. $\mathrm{R}_{\mathrm{ct}}$ element is characterized by the charge transfer resistance of the interface metal / electrolyte, associated with the process of oxidation of metal, while the constant phase element CPEdl - double layer capacitance, occurring on the border of phases under consideration. 


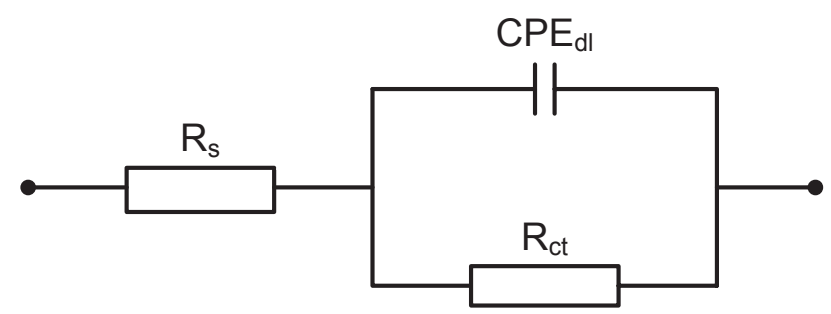

Fig.1. The selected replacement of corrosion electrical circuit

For the selected alternative resultant impedance of the circuit can be described by the following relationship:

$$
Z=R_{s}+\frac{1}{\frac{1}{R_{c t}}+Y_{d l}(j \omega)^{n_{d l}}} .
$$

In this case, the impedance of the constant phase element $\left(\mathrm{CPE}_{\mathrm{dl}}\right)$ describes relationship:

$$
Z_{C P E_{d l}}=\frac{1}{Y_{d l}(j \omega)^{n_{d l}}},
$$

where:

$\mathrm{Y}_{\mathrm{dl}}, \mathrm{n}_{\mathrm{dl}}$ - parameters determined during the study, describing the capacitive impedance.

To evaluate the susceptibility to electrochemical corrosion uses statistical analysis using the computer program STATISTICA 5.5. Formulated the hypothesis, assuming the level of significance $\mathrm{p}=0.05$, which assumes that the results of individual samples from AW-7020 alloy and bonded connections in corrosive environments are the same (from the same population). To verify the hypothesis test U Mann-Whitney test was used.

\section{The research results}

The results of the electrochemical impedance spectroscopy of samples of 7020 alloy native material and the MIG joints were computer processed. As a result, set the parameters characterizing the corrosion process, where the average values of five samples are presented in Tab. 3. These parameters define the individual components of the model - a replacement circuit chosen in accordance with the methodology of the study.

Tab. 3. The parameters of the replacement corrosive electrical circuit of alloy 7020 and its joints welded by MIG method

\begin{tabular}{|c|c|c|c|c|c|c|c|c|}
\hline \multirow{2}{*}{ Specimen } & \multirow{2}{*}{$\begin{array}{c}\mathrm{R}_{\mathrm{s}} \\
{\left[\Omega^{*} \mathrm{~cm}^{2}\right]}\end{array}$} & $\begin{array}{c}\text { Std. } \\
\text { Dev. }\end{array}$ & $\begin{array}{c}\mathrm{R}_{\mathrm{ct}} \\
{\left[\Omega^{*} \mathrm{~cm}^{2}\right]}\end{array}$ & \multirow{2}{*}{$\begin{array}{c}\text { Std. } \\
\text { Dev. }\end{array}$} & \multicolumn{4}{|c|}{$\mathrm{CPE}_{\mathrm{dl}}$} \\
\cline { 6 - 10 } & & & $\mathrm{Y}_{\mathrm{dl}}$ & $\begin{array}{c}\left.\mathrm{Std} \mathrm{s}^{\mathrm{n}-1} / \mathrm{cm}^{2}\right] \\
\text { Dev. }\end{array}$ & $\mathrm{n}_{\mathrm{dl}}$ & $\begin{array}{c}\text { Std. } \\
\text { Dev. }\end{array}$ \\
\hline Native material & 0.681 & 0.15 & 522.18 & 35.74 & 21.47 & 1.16 & 0.962 & 0.02 \\
\hline $\mathrm{MIG}$ & 0.776 & 0.19 & 334.53 & 55.61 & 20.16 & 1.37 & 0.917 & 0.02 \\
\hline
\end{tabular}

Std. Dev. - the standard deviation

The results of the electrochemical impedance spectroscopy are also shown graphically in Nyquist charts (Fig. 2 and 3), and matched them with the theoretical curve. Statistical analysis was tested using the U Mann-Whitney, the results shown in Tab. 4. 
Tab. 4. The value of significance level " $p$ " obtained from the test U Mann-Whitney for alloy 7020 and the MIG joints in an attempt to EIS

\begin{tabular}{|c|c|}
\hline Parameter & The level of significance "p" \\
\hline $\mathrm{R}_{\mathrm{s}}$ & 0.464 \\
\hline $\mathrm{R}_{\mathrm{ct}}$ & 0.009 \\
\hline $\mathrm{Y}_{\mathrm{dl}}$ & 0.174 \\
\hline $\mathrm{n}_{\mathrm{dl}}$ & 0.016 \\
\hline
\end{tabular}

The statistical analysis shows that there are significant differences especially for the parameter $R_{\text {ct. }}$ The significance level " $p$ " is much smaller than the established cut-off value of 0.05 . Electrolyte resistance $R_{s}$ for all the cases is statistically the same as confirmed by the tests under comparable conditions are present.

Considering the capacitive impedance component $\mathrm{n}_{\mathrm{dl}}$ can be seen that the native material and joints welded by MIG have statistical difference. The lower value of this parameter indicates more irregular corrosion process what means greater susceptibility to pitting corrosion occurrence.

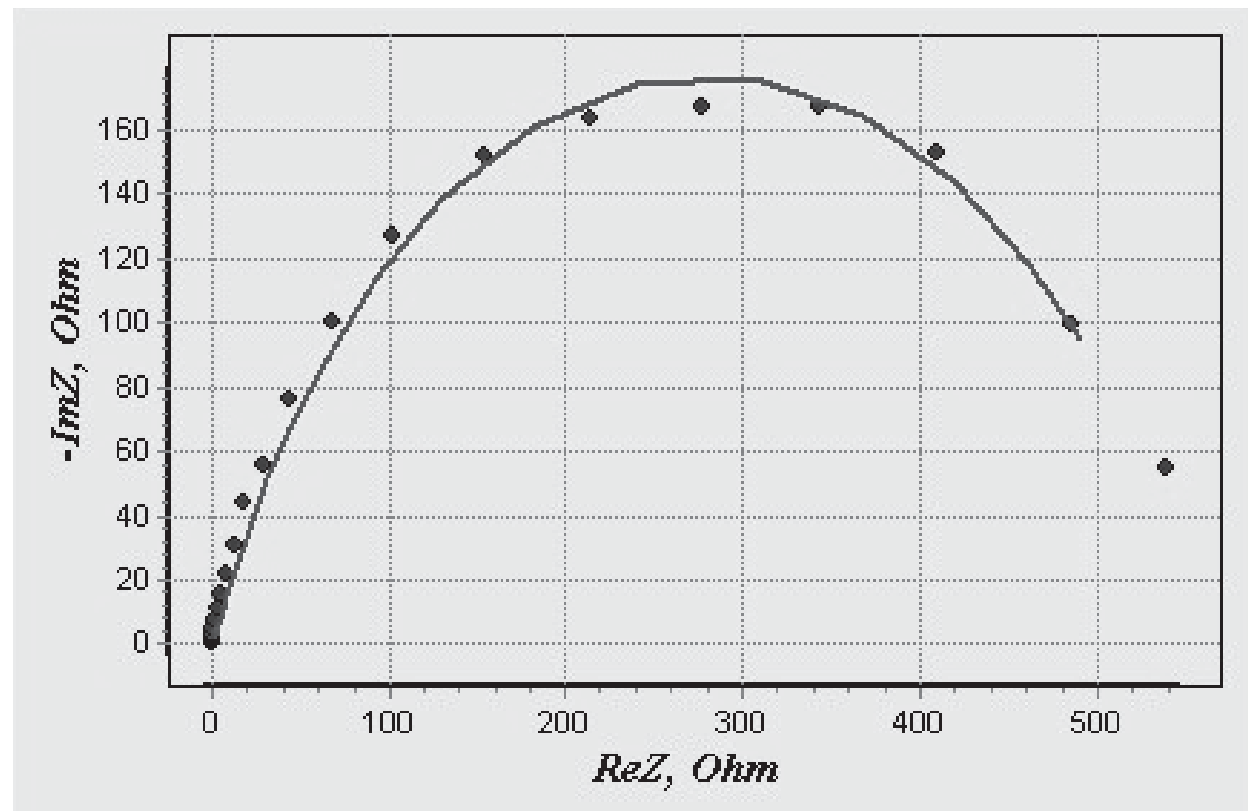

Fig. 2. An example of the Nyquist chart for a sample of the native material 7020

\section{Summary}

Analysis of the electrochemical impedance spectroscopy in the study data showed that the native material has more resistance to electrochemical corrosion than MIG welded joint. Charge transfer resistance value by a double layer of $\mathrm{R}_{\mathrm{ct}}$ is smaller for a sample welded by MIG which indicates a lower resistance to withstand the charge exchange (ions, electrons) between the material and the electrolyte. $R_{\text {ct }}$ parameter value during the test for sample of the native material, reached about $58 \%$ higher than the joint welded by MIG.

The second parameter describing the corrosion process is the double layer capacitance $C P E_{\mathrm{dl}}$. For researched specimens $\mathrm{Y}_{\mathrm{dl}}$ capacitive component takes almost the same values (there is no statistical difference). This parameter is not as important in the evaluation of corrosion resistance as electrochemical charge-transfer resistance $\mathrm{R}_{\mathrm{ct}}[10]$. 


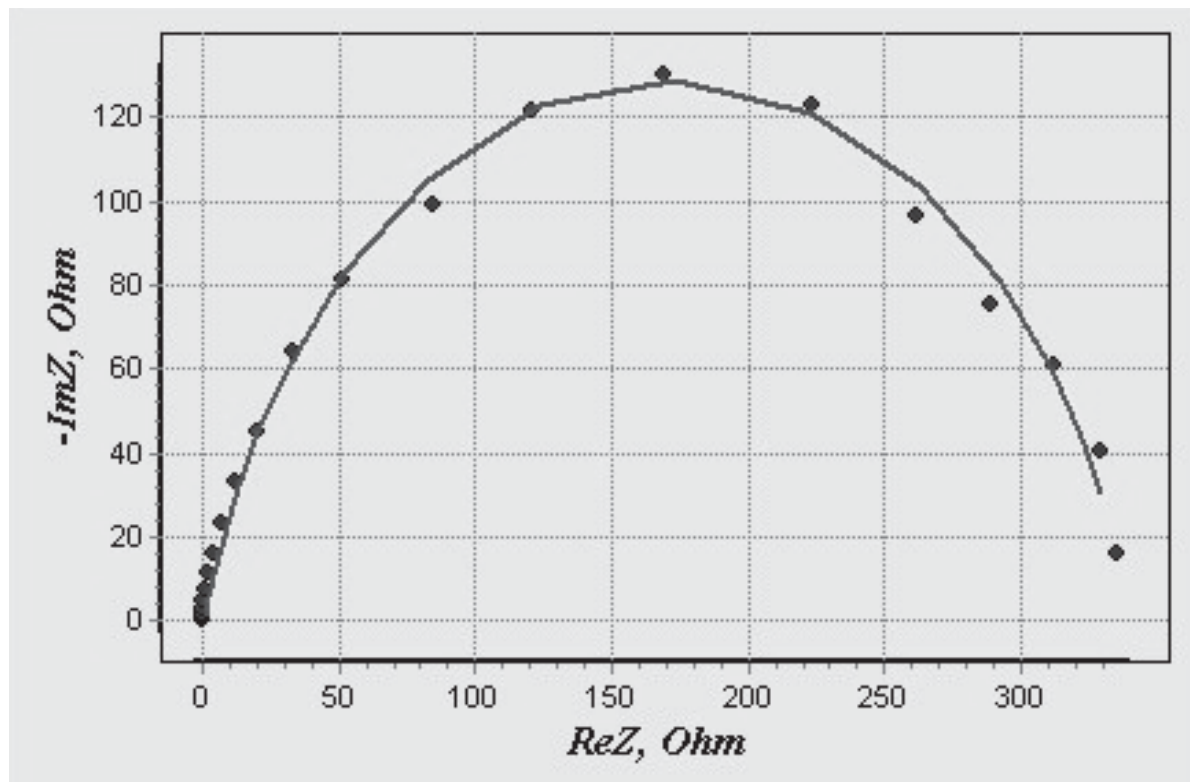

Fig. 3. An example of the Nyquist chart for a sample welded by MIG

The component power exponent of capacitive impedance $\mathrm{n}_{\mathrm{dl}}$ (of equivalent circuit), determining the homogeneity of corrosion is lower for joints welded by MIG then for the native metal. This indicates a greater tendency to pitting corrosion was for MIG joints. Despite the differences in values that occur $n_{\mathrm{dl}}$ parameter for each sample the values are relatively high which indicates a high homogeneity of the processes of corrosion.

Electrolyte resistance $R_{s}$ which is corrosive environment for all the samples was the same level and to receive very low values (several hundred times smaller than the charge transfer resistance), which indicates a very high electrical conductivity of the solution. This parameter is not critical in the consideration of corrosion resistance of the samples.

In summary, studies on the electrochemical corrosion resistance made by the method EIS showed that the MIG welded joint is less resistant than native material AW-7020 for this type of degradation in sea water environment.

\section{References}

[1] Czechowski, M., Effect of anodic polarization on stress corrosion cracking of some aluminium alloys, Advances in Materials Science, Vol. 7, pp. 13-20, No. 1(11), 2007.

[2] Czechowski, M., Low-cycle fatigue of friction stir welded Al-Mg alloys, Journal of Materials Processing Technology, 164-165, 1001-1006, 2005.

[3] Czechowski, M., Własności złączy doczołowych blach ze stopów Al-Mg spajanych różnymi metodami, Materiały i Technologie, Politechnika Gdańska, Nr 1(1) 2003, Gdańsk 2003.

[4] Czechowski, M., Zieliński, A., Effect of cathodic polarization on failure and degradation of mechanical properties of some aluminium alloys, Scripta Metallurgy Materials, Vol. 30, 1994.

[5] Dudzik, K., Czechowski, M., Analysis of possible shipbuilding application of Friction Stir Welding (FSW) method to joining elements made of AlZn5Mg1 alloy, Polish Maritime Research, No. 4, 2009.

[6] Dyl, T., Starosta, R., Effect of the ceramic dispersion in the nickel matrix composite coatings on corrosion properties after plastic working, Solid State Phenomena, Vol. 183, 2012.

[7] Starosta, R., Corrosion of $\mathrm{Ni}-\mathrm{Al}$ and $\mathrm{Ni}-\mathrm{Al}-\mathrm{Al}_{2} \mathrm{O}_{3}$ flame sprayed coatings of Casto-Dyn 8000 system in $0.01 \mathrm{M} \mathrm{H}_{2} \mathrm{SO}_{4}$ and 3.5\% NaCl solution, Solid State Phenomena, Vol. 183, 2012.

[8] Starosta, R., The influence of plastic strain on the corrosive properties of plasma sprayed intermetallic NiAl and $\mathrm{NI}_{3}$ Al coatings, Solid State Phenomena, Vol. 165, pp. 165-177, 2010. 
[9] Starosta, R., Zieliński, A., Effect of chemical composition on corrosion and wear behaviour of the composite $\mathrm{Ni}-\mathrm{Fe}-\mathrm{Al}_{2} \mathrm{O}_{3}$ coating, Journal of Materials Processing Technology, No. 157-158, 2004.

[10] Xiao, Y. P., Pan, Q. L., Li, W. B., Liu, X. Y., He, Y. B., Influence of retrogression and reaging treatment on corrosion behaviour of Al- $\mathrm{Zn}-\mathrm{Mg}-\mathrm{Cu}$ alloy, Materials and Design 32, China 2011. 